\title{
The Purification and Properties of Two Isofunctional 2-Hydroxy- 6-oxohepta-2,4-dienoate Hydrolases from Alcaligenes eutrophus Strain 345
}

\author{
By RONALD C. BAYLY,* DARIO DIBERARDINO, E. JOHN L. HUGHES $\dagger$ \\ AND RONALD A. SKURRAY \\ Department of Microbiology, Monash University, Clayton 3168, Victoria, Australia
}

(Received 27 June 1986; revised 14 October 1986)

\begin{abstract}
Two 2-hydroxy-6-oxohepta-2,4-dienoate (HOD) hydrolases have been purified to homogeneity from Alcaligenes eutrophus ATCC 17707. One, HODHII, is encoded by the TOL-like plasmid, pRA1000, and the other, HODHI, is chromosomally-encoded. HODHI and HODHII have an $M_{\mathrm{r}}$ of $104 \times 10^{3}$ and $116 \times 10^{3}$, respectively, and both are dissociated by SDS into three subunits of equal size which are not linked by disulphide bonds. Both hydrolases are active against a similar range of substrates formed by the action of catechol 2,3-oxygenases, generally being more active against substrates formed from 3-alkyl- rather than 4-alkyl-substituted catechols. HODHI and HODHII had similar $K_{\mathrm{m}}$ values for HOD, but HODHI had a significantly lower $K_{\mathrm{m}}$ value for, and a higher activity against, 2-hydoxymuconic semialdehyde than HODHII. It was shown by immunodiffusion studies that the two hydrolases were immunologically distinct and that HODHI had no common antigenic determinants with HOD hydrolases from the Pseudomonas putida strains NCIB 9865, NCIB 10015 and mt-2; HODHII gave a line of identity with antiserum to the hydrolase from $P$. putida NCIB 9865 . A comparison of the physico-chemical properties of HODHI and HODHII with the same properties of the HOD hydrolases from the three $P$. putida strains demonstrated several similarities between the five HOD hydrolases which have been purified.
\end{abstract}

\section{INTRODUCTION}

In our studies on the degradation of $m$-toluate and phenol by Alcaligenes eutrophus strain 345 (ATCC 17707) via meta-cleavage pathways, we reported that the 2-hydroxymuconic semialdehyde hydrolase, HMSHII, elicited during growth on $m$-toluate, had different substrate specificities from the corresponding enzyme, HMSHI, when the growth substrate was phenol (Hughes et al., 1984b). We also reported that HMSHII was encoded on an $85 \mathrm{~kb}$ plasmid, pRA1000, whereas HMSHI was chromosomally-encoded.

Bayly \& DiBerardino (1978) reported the purification and properties of hydrolases carrying out the same functions as HMSHI and II, from two different isolates of Pseudomonas putida biotype A, and more recently, Duggleby \& Williams (1986) have reported the isolation and characterization of a plasmid-encoded hydrolase from $P$. putida mt-2, which carries the $117 \mathrm{~kb}$ TOL plasmid, pWW0. We now report the purification of HMSHI and HMSHII and present a comparison of some of their properties with those of the isofunctional hydrolases previously reported. For the reasons given by Duggleby \& Williams (1986), viz. that 'the physiologically most important substrate' for such hydrolases is 2-hydroxy-6-oxohepta-2,4-dienoate (HOD), we shall refer to the hydrolases HMSHI and HMSHII as HODHI and HODHII, respectively.

† Present address: Department of Biology, Yale University, New Haven, Connecticut, USA.

Abbreviations: HMS, 2-hydroxymuconic semialdehyde; HOD, 2-hydroxy-6-oxohepta-2,4-dienoate; HODH, 2hydroxy-6-oxohepta-2,4-dienoate hydrolase. 


\section{METHODS}

Organisms, method of cultivation and preparation of cell extracts. A. eutrophus strain 345 (ATCC 17707) was obtained from P. J. Chapman, University of Minnesota, and was maintained as described by Hughes $e t$ al. $(1984 a)$; some of its metabolic properties have been described (Hughes et al., 1984a,b). To obtain cells from which HODHII was to be purified, strain 345 was grown in the presence of $m$-toluate. For the purification of HODHI, a derivative of strain 345,RA1012, which had been cured of the plasmid pRA1000 (Hughes et al., 1984a) was grown in the presence of phenol. Cells were grown and cell extracts were prepared as described previously (Bayly \& DiBerardino, 1978), except that DL-lactate $(20 \mathrm{~mm})$ replaced fumarate as the basal carbon source. The concentration of protein in cell extracts and fractions was determined by the method of Lowry.

Physicochemical and immunological examination of purified hydrolase preparations. $M_{\mathrm{r}}$ values of the native enzymes were determined from sedimentation equilibrium data essentially as described by Yphantis (1964). Analytical polyacrylamide disc gel electrophoresis (PAGE) was by the method of Davis (1964) using a 7.5\% (w/v) gel with $2.5 \%(w / v)$ cross-linker at pH 8.9. SDS-PAGE was done as described by Weber \& Osborn (1969), using $10 \%$ gels. The following standards were used to determine subunit size : bovine serum albumin (68000), ovalbumin (45000), chymotrypsinogen (25000), all from Boehringer, and lysozyme (14400) from Sigma. Reduced and non-reduced samples for SDS-PAGE were prepared as described by Tack et al. (1972). Amino acid analyses of the purified enzymes were done on samples (1-2 mg protein) which were prepared and analysed as described by Bayly \& DiBerardino (1978); duplicate analyses were not done. Heat stability and immunological studies were done as described by Bayly \& DiBerardino (1978).

Determination of $K_{\mathrm{m}}$ values for HODHI and II against HOD and 2-hydroxymuconic semialdehyde (HMS) were calculated from Lineweaver-Burk plots. Enzymes were assayed in triplicate at substrate concentrations ranging from 70 to $2 \mu \mathrm{M}$ for HOD and from 170 to $3 \mu \mathrm{M}$ for HMS; at least 15 different concentrations of substrate were used over each range. The relative activity against different substrates was determined at $\mathrm{pH} 7.6$ using substrate concentrations of approximately $70 \mu \mathrm{M}$.

Enzyme assays. All assays for activity of the hydrolases against the meta-cleavage products of catechol and some of its homologues were done in a final reaction volume of $3 \mathrm{ml}$ and at $23{ }^{\circ} \mathrm{C}$. The reaction mixture contained $33 \mathrm{~mm}-\mathrm{KH}_{2} \mathrm{PO}_{4}(\mathrm{pH} 7 \cdot 6$ ), approximately $0.2 \mu \mathrm{mol}$ substrate (prepared as described by Bayly \& DiBerardino 1978), and enzyme. The specific activities were calculated using the molar absorption coefficients reported by Bayly et al. (1966) and Bayly \& DiBerardino (1978). The unit of activity is defined as $\mu \mathrm{mol}$ substrate $\mathrm{min}^{-1}\left(\mathrm{mg}^{\circ}\right.$ protein $)^{-1}$.

Chemicals. 3,4-Dimethylcatechol and 3-isopropylcatechol were gifts from P. J. Chapman and Coalite and Chemical Products, Bolsover, UK, respectively. Catechol, and 3-methyl- and 4-methylcatechol were from Aldrich. All catechols were purified by vacuum sublimation before use.

Purification of HODHI and HODHII. The procedures used for both enzymes were essentially the same and, with the exception of the last step, differed only in such details as the volume of samples applied to columns, the volume of fractions collected and the flow rate of eluants. All steps were done at $2-4{ }^{\circ} \mathrm{C}$. For HODHI, approximately $500 \mathrm{~g}$ wet weight of cells was used to prepare the crude cell extract and, for HODHII, approximately $270 \mathrm{~g}$ wet weight of cells was used.

Step 1. Cell extracts were brought to either $30 \%$ saturation (HODHI) or $20 \%$ saturation (HODHII) by the slow addition of solid $\left(\mathrm{NH}_{4}\right)_{2} \mathrm{SO}_{4}$ and, after equilibration for $30 \mathrm{~min}$, the precipitated protein was removed by centrifugation at $20000 \mathrm{~g}$ for $15 \mathrm{~min}$. The supernatant solution was brought to $50 \%$ saturation (HODHI) and $40 \%$ saturation (HODHII) with $\left(\mathrm{NH}_{4}\right)_{2} \mathrm{SO}_{4}$ and, after equilibration, the precipitate was collected by centrifugation and dissolved in $0.05 \mathrm{M}$-Tris/ $\mathrm{HCl}$ buffer, $\mathrm{pH} 7.8$. The solutions were dialysed against the same buffer until free of ammonium ions as shown by testing with Nessler's reagent.

Step 2. The dialysed solutions were applied to DEAE-cellulose columns $(5 \times 50 \mathrm{~cm})$ which had been previously equilibrated with $0.05 \mathrm{M}$-Tris $/ \mathrm{HCl}, \mathrm{pH} \mathrm{7.8}$; the protein was eluted with 21 of a linear gradient of $0-1.0 \mathrm{M}-\mathrm{NaCl}$ in the same buffer. Pooled active enzyme fractions were dialysed against $0.05 \mathrm{M}-\mathrm{Tris} / \mathrm{HCl}, \mathrm{pH} 7.8$.

Step 3. The dialysed enzyme fractions were applied to DEAE-cellulose columns $(2.5 \times 30 \mathrm{~cm})$ equilibrated as above and the protein was eluted with $800 \mathrm{ml}$ of a linear gradient of $0-0.5 \mathrm{M}-\mathrm{NaCl}$ in the same buffer.

Step 4. Fractions with activity of at least $20 \%$ of that in the most active fraction were pooled, concentrated to $5 \mathrm{ml}$ by ultrafiltration (PM-30 Amicon membrane), applied to a Sephadex G-200 column $(2.6 \times 60 \mathrm{~cm})$ and eluted with $0.05 \mathrm{M}$-Tris/ $\mathrm{HCl}, \mathrm{pH} 8 \cdot 2$.

Step 5. Pooled fractions, selected as in step 4, were dialysed against $0.5 \mathrm{M}$-Tris/HCl, $\mathrm{pH} 8 \cdot 2$, applied to a DEAESepharose column $(2.5 \times 30 \mathrm{~cm})$ and the protein was eluted with $500 \mathrm{ml}$ of a linear gradient of $0-1.0 \mathrm{M}-\mathrm{NaCl}$ in the same buffer.

Step 6. For HODHI, the pooled fractions were concentrated to $5 \mathrm{ml}$ as above, applied to a Sephadex G-150 column $(2.6 \times 60 \mathrm{~cm})$ previously equilibrated with $0.05 \mathrm{M}$-Tris $/ \mathrm{HCl}, \mathrm{pH} 7.8$ and the protein was eluted with the same buffer.

For HODHII, the pooled fractions from step 5 were dialysed against $0.05 \mathrm{M}-\mathrm{Tris} / \mathrm{HCl}, \mathrm{pH} 7 \cdot 5$, applied to a 
DEAE-cellulose column $(2.5 \times 30 \mathrm{~cm})$ equilibrated with the same buffer and the protein was eluted with a linear gradient of $0-0.3 \mathrm{M}-\mathrm{NaCl}$ in the same buffer.

Fractions in which the elution profile for protein was coincident with enzyme activity were examined by PAGE and the fractions were pooled and stored at $4{ }^{\circ} \mathrm{C}$. Samples of the pooled fractions to be used for amino acid analysis and for the production of antisera were dialysed to remove salts and then lyophilized. Examinations for substrate specificity, $K_{\mathrm{m}}$ values, $\mathrm{pH}$ optima, inhibition/activation studies, $M_{\mathrm{r}}$ and subunit structure were completed within $7 \mathrm{~d}$ of step 6.

\section{RESULTS}

A summary of the purification procedures and the yields obtained for HODHI and HODII is shown in Table 1.

PAGE of fraction 86, step 6, which contained the peak activity of HODHI, showed a major and a minor protein band (Fig. 1a). A densitometer tracing of this gel showed that the major band constituted about $93 \%$ of the protein. The same pattern was obtained with fractions 78-94 (step 6) and these fractions were pooled. Elution of the protein bands from an unstained gel showed the main band to be active against HOD whereas the minor band was inactive. Sedimentation equilibrium analysis of the pooled fractions showed HODHI to have an $M_{\mathrm{r}}$ of $104 \times 10^{3}$. SDS-PAGE showed a major band corresponding to an $M_{\mathrm{r}}$ of $34.4 \times 10^{3}$, which was unaltered when the protein was reduced with 2-mercaptoethanol before electrophoresis. HODHI therefore appears to be a trimer of subunits of identical size which are not linked by disulphide bonds.

The peak of activity of HODHII was in fraction 63, step 6; PAGE of this fraction showed five protein bands (Fig. 1 b) ; the same pattern was observed with each of fractions $60-76$ from step 6 , which were pooled and used for all further procedures.

Segments from each of three unstained gels of fraction 63 were cut out as indicated in Fig. $1(b)$; the protein was eluted from each segment with $0.1 \mathrm{ml} 0.05 \mathrm{M}-\mathrm{Tris} / \mathrm{HCl}, \mathrm{pH} 7.5$, and assayed against HOD, HMS and 2-hydroxy-5-methylmuconic semialdehyde. The eluate from each segment of gel had relative activities against those substrates in the ratio $100: 14: 5$, respectively, which is approximately the same as that for fraction 63 before PAGE and also for crude extract of strain 345 grown in the presence of $m$-toluate (Hughes $e t a l ., 1984 b$ ). On this basis it seems that none of the protein bands from fraction 63 correspond to HODHI as the ratio of activities of HODHI against the same substrates is quite different (see Table 3).

Sedimentation equilibrium analysis showed HODHII to have an $M_{\mathrm{r}}$ of $116 \times 10^{3}$. SDSPAGE of HODHII showed a single protein band corresponding to an $M_{\mathrm{r}}$ of $36.7 \times 10^{3}$; HODHII therefore appears to be a trimer of identically sized subunits. There was no difference in the electrophoretic mobility of the protein before and after reduction with 2-mercaptoethanol, which indicated that, like those of HODHI, the subunits of HODHII are not linked by disulphide bonds.

Even though multiple bands were obtained from PAGE of HODHII the finding of only a single protein band following SDS-PAGE indicates that HODHII had been purified to homogeneity. It is probable that the multiple bands observed were due to dissociation or aggregation of the protein during electrophoresis, especially as bands eluted from each of the three segments of the gel (Fig $1 b$ ) all showed the same enzyme activity as the sample before electrophoresis. Keat \& Hopper (1978) reported a similar observation with $p$-cresol methylhydroxylase purified from $P$. putida NCIB 9869, where all three bands obtained on PAGE had enzyme activity. A maleylpyruvate hydrolase purified from $P$. alcaligenes by Bayly $e t$ al. (1980) also behaved similarly.

\section{Immunological specificity}

Antisera prepared against each purified hydrolase were examined by Ouchterlony double diffusion against both purified enzymes. A single precipitin band was formed between each and its homologous antiserum. No precipitin bands were observed when the antiserum to HODHI was tested against purified HODHII (and vice versa) and against each of the purified HOD hydrolases from $P$. putida NCIB 10015 and NCIB 9865, or against a crude extract of $m$-toluate- 
Table 1. Summary of the procedures used in the purification of HODHI and HODHII from A. eutrophus 345

\begin{tabular}{|c|c|c|c|c|c|c|c|}
\hline Step & Procedure & $\begin{array}{l}\text { Total } \\
\text { volume } \\
(\mathrm{ml})\end{array}$ & $\begin{array}{l}\text { Total } \\
\text { protein } \\
(\mathrm{mg})\end{array}$ & $\begin{array}{l}\text { Specific } \\
\text { activity* }\end{array}$ & $\begin{array}{l}\text { Total } \\
\text { activity } \\
\text { (units) }\end{array}$ & $\begin{array}{l}\text { Purific- } \\
\text { ation } \\
\text { (fold) }\end{array}$ & $\begin{array}{l}\text { Recovery } \\
(\%)\end{array}$ \\
\hline & HODHI & & & & & & \\
\hline & Crude extract $\dagger$ & 1150 & 52500 & $0 \cdot 18$ & 9450 & - & 100 \\
\hline 1 & Ammonium sulphate & & & & & & \\
\hline & $(30-50 \%)$ & 570 & 19900 & 0.19 & 3780 & $1 \cdot 1$ & 40 \\
\hline 2 & DEAE-cellulose; & & & & & & \\
\hline 3 & $\begin{array}{l}0-1.0 \mathrm{M}-\mathrm{NaCl}-0.05 \mathrm{M} \text {-Tris (pH 7.8) } \\
\text { DEAE-cellulose. }\end{array}$ & 355 & 2020 & 0.81 & 1640 & $4 \cdot 5$ & 17 \\
\hline & $0-0.5 \mathrm{M}-\mathrm{NaCl}-0.05 \mathrm{M}-\mathrm{Tris}(\mathrm{pH} 7.8)$ & $16 \cdot 5$ & 1630 & 0.64 & 1040 & 3.55 & 11 \\
\hline 4 & Sephadex G-200 & & & & & & \\
\hline 5 & $\begin{array}{l}0.05 \mathrm{M} \text {-Tris (pH } 8 \cdot 2) \\
\text { DEAE-Sepharose: }\end{array}$ & 4 & 272 & 3.52 & 957 & $19 \cdot 5$ & 10 \\
\hline & $0-1.0 \mathrm{M}-\mathrm{NaCl}-0.05 \mathrm{M}-\mathrm{Tris}(\mathrm{pH} 8.2)$ & $1 \cdot 3$ & 112 & $5 \cdot 15$ & 577 & 28.6 & 6 \\
\hline 6 & $\begin{array}{l}\text { Sephadex G- } 150 \\
0.05 \mathrm{M} \text {-Tris }(\mathrm{pH} 7.8)\end{array}$ & 11.5 & 30 & 17.4 & 522 & 96.6 & 5.5 \\
\hline 1 & $\begin{array}{l}\text { HODHII } \\
\text { Crude extract } \ddagger \\
\text { Ammonium sulphate }\end{array}$ & 1000 & 27200 & 0.26 & 7080 & - & 100 \\
\hline & $(20-40 \%)$ & 260 & 8840 & 0.67 & 5920 & $2 \cdot 6$ & 84 \\
\hline 2 & $\begin{array}{l}\text { DEAE-cellulose; } \\
0-1.0 \mathrm{M}-\mathrm{NaCl}-0.05 \mathrm{M} \text {-Tris (pH 7.8) }\end{array}$ & 260 & 2940 & 1.7 & 5000 & 6.5 & 71 \\
\hline 3 & $\begin{array}{l}\text { DEAE-cellulose; } \\
0-0.5 \mathrm{M}-\mathrm{NaCl}-0.05 \mathrm{M}-\mathrm{Tris}(\mathrm{pH} 7.8)\end{array}$ & 25 & 1260 & 3.97 & 5000 & $15 \cdot 2$ & 71 \\
\hline 4 & Sephadex G-200; & & & & & & \\
\hline & $0.05 \mathrm{M}$-Tris (pH 8.2) & 39 & 162 & $10 \cdot 4$ & 1680 & 40 & 24 \\
\hline 5 & $\begin{array}{l}\text { DEAE-Sepharose; } \\
0-1.0 \mathrm{M}-\mathrm{NaCl}-0.05 \mathrm{M} \text {-Tris ( } \mathrm{pH} 8.2)\end{array}$ & 14.5 & 113 & 10.8 & 1220 & 41.5 & 17 \\
\hline 6 & $\begin{array}{l}\text { DEAE-cellulose; } \\
0-0.3 \mathrm{M}-\mathrm{NaCl}-0.05 \mathrm{M}-\mathrm{Tris}(\mathrm{pH} 7.5)\end{array}$ & 1.5 & 30 & $10 \cdot 1$ & 303 & 39 & $4 \cdot 2$ \\
\hline
\end{tabular}

grown $P$. putida mt-2. These results indicated that HODHI shared no common antigenic determinants with either its isofunctional enzyme, HODHII, or the other hydrolases tested.

When the antiserum to HODHII was tested against the purified hydrolase from $P$. putida NCIB 10015 and a crude extract of $m$-toluate-grown $P$. putida $\mathrm{mt}-2$, no precipitin bands were detected. However each of HODHII, the purified hydrolase from $P$. putida NCIB 9865 , and crude extract of $m$-toluate-grown $P$. putida mt-2 all gave a line of identity with the antiserum to purified hydrolase of $P$. putida NCIB 9865 .

\section{Amino acid composition}

The amino acid compositions of HODHI and HODHII (Table 2) show a high degree of similarity, differing significantly only in the number of valine residues per mole. The low cysteine values in both enzymes are in agreement with the observation that the subunits of these enzymes are not linked by disulphide bonds. The same unidentified amino acid was detected in similar amounts in both hydrolases.

\section{Heat stability and pH optima}

Both HODHI and HODHII were similar in their sensitivity to heat. No activity of HODHII was present after treatment for $2 \mathrm{~min}$ at $45^{\circ} \mathrm{C}$ and HODHI was inactivated after 4 min at the same temperature.

Both enzymes showed maximal activity at $\mathrm{pH} 8.6$ and had a similar profile of activity over the 
1

(a)

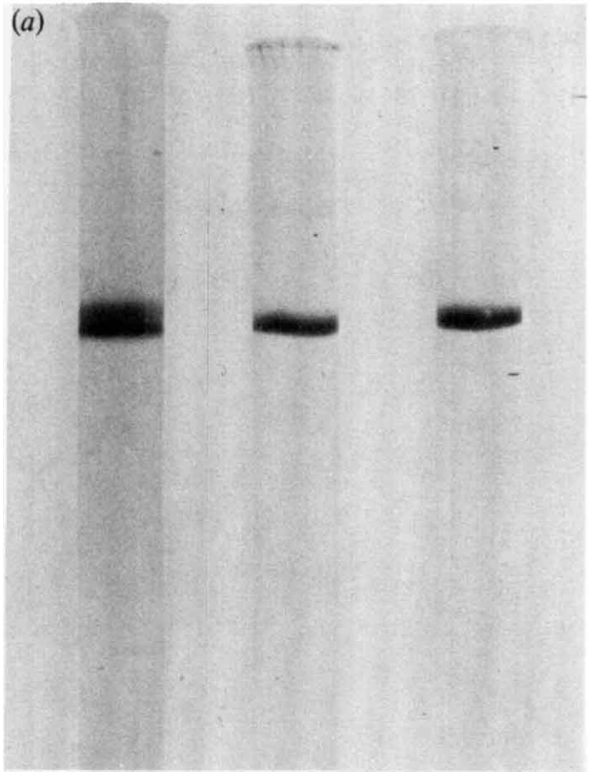

2

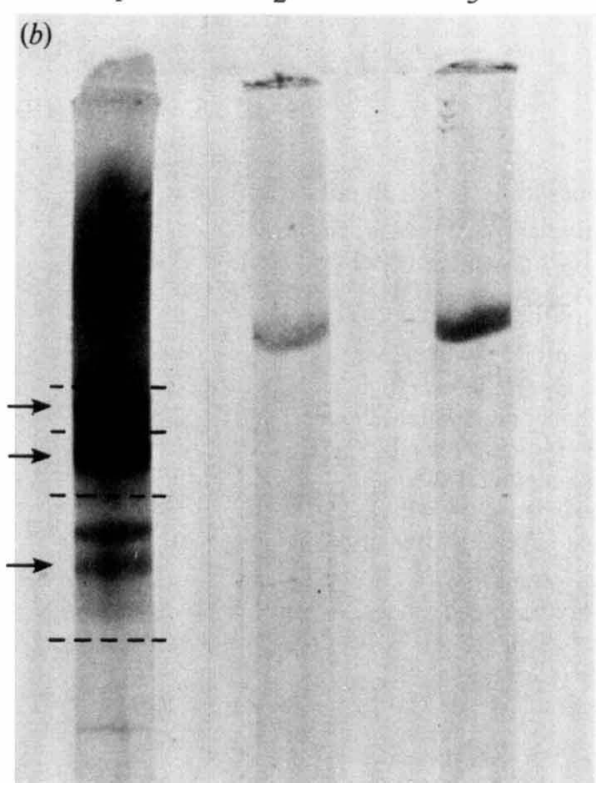

Fig. 1. Polyacrylamide gel electrophoresis of (a) HODHI and (b) HODHII. (1) PAGE, (2) SDS-PAGE, non-reduced, (3) SDS-PAGE, reduced. The arrows indicate those segments which were cut out of corresponding unstained gels and whose relative activities were tested against substrates (i)-(iii) listed in Table 3.

Table 2. Amino acid compositions of HODHI and HODHII from A. eutrophus

\begin{tabular}{|c|c|c|c|c|}
\hline \multirow[b]{2}{*}{ Amino acid } & \multicolumn{2}{|c|}{ HODHI } & \multicolumn{2}{|c|}{ HODHII } \\
\hline & $\begin{array}{l}\text { Percentage composition } \\
\left.\text { [g }(100 \mathrm{~g} \text { protein })^{-1}\right]\end{array}$ & $\begin{array}{c}\text { Residues per } \\
34000 \mathrm{~g}^{*}\end{array}$ & $\begin{array}{l}\text { Percentage composition } \\
{\left[\mathrm{g}(100 \mathrm{~g} \text { protein })^{-1}\right]}\end{array}$ & $\begin{array}{l}\text { Residues per } \\
37000 \mathrm{~g}^{*}\end{array}$ \\
\hline Cysteine & 0.8 & 2 & 0.6 & 2 \\
\hline Aspartic acid & $10 \cdot 2$ & 30 & $10 \cdot 2$ & 28 \\
\hline Threonine & 4.5 & 13 & $4 \cdot 3$ & 12 \\
\hline Serine & 5.9 & 17 & 4.7 & 13 \\
\hline Glutamic acid & $8 \cdot 1$ & 24 & $9 \cdot 2$ & 25 \\
\hline Glycine & $10 \cdot 8$ & 32 & 9.9 & 28 \\
\hline Alanine & $12 \cdot 9$ & 38 & $12 \cdot 4$ & 34 \\
\hline Valine & $8 \cdot 8$ & 26 & 5.8 & 16 \\
\hline Methionine & 0 & 0 & 0 & 0 \\
\hline Isoleucine & $4 \cdot 4$ & 13 & $6 \cdot 1$ & 12 \\
\hline Leucine & 10.7 & 31 & 11.6 & 32 \\
\hline Tyrosine & 0 & 0 & 0 & 0 \\
\hline Phenylalanine & $3 \cdot 3$ & 10 & 3.8 & 10 \\
\hline Histidine & 0 & 0 & 0 & 0 \\
\hline Lysine & $3 \cdot 1$ & 9 & $2 \cdot 0$ & 6 \\
\hline Arginine & 6.5 & 19 & $7 \cdot 3$ & 20 \\
\hline Proline & $5 \cdot 4$ & 16 & 5.8 & 16 \\
\hline Unidentified & $4 \cdot 1$ & - & $5 \cdot 3$ & - \\
\hline
\end{tabular}

\footnotetext{
* Equivalent to residues per mole of subunit, given to the nearest integer.
}

$\mathrm{pH}$ range $5 \cdot 0-10 \cdot 0$. In both cases there was a marked decrease in activity above $\mathrm{pH} 9 \cdot 0$. At $\mathrm{pH} 7 \cdot 6$, at which assays were routinely done, the activity of HODHI and II was about $75-80 \%$ of that at $\mathrm{pH} 8 \cdot 6$. 
Table 3. Comparison of properties of HODHs from strains of A. eutrophus and P. putida

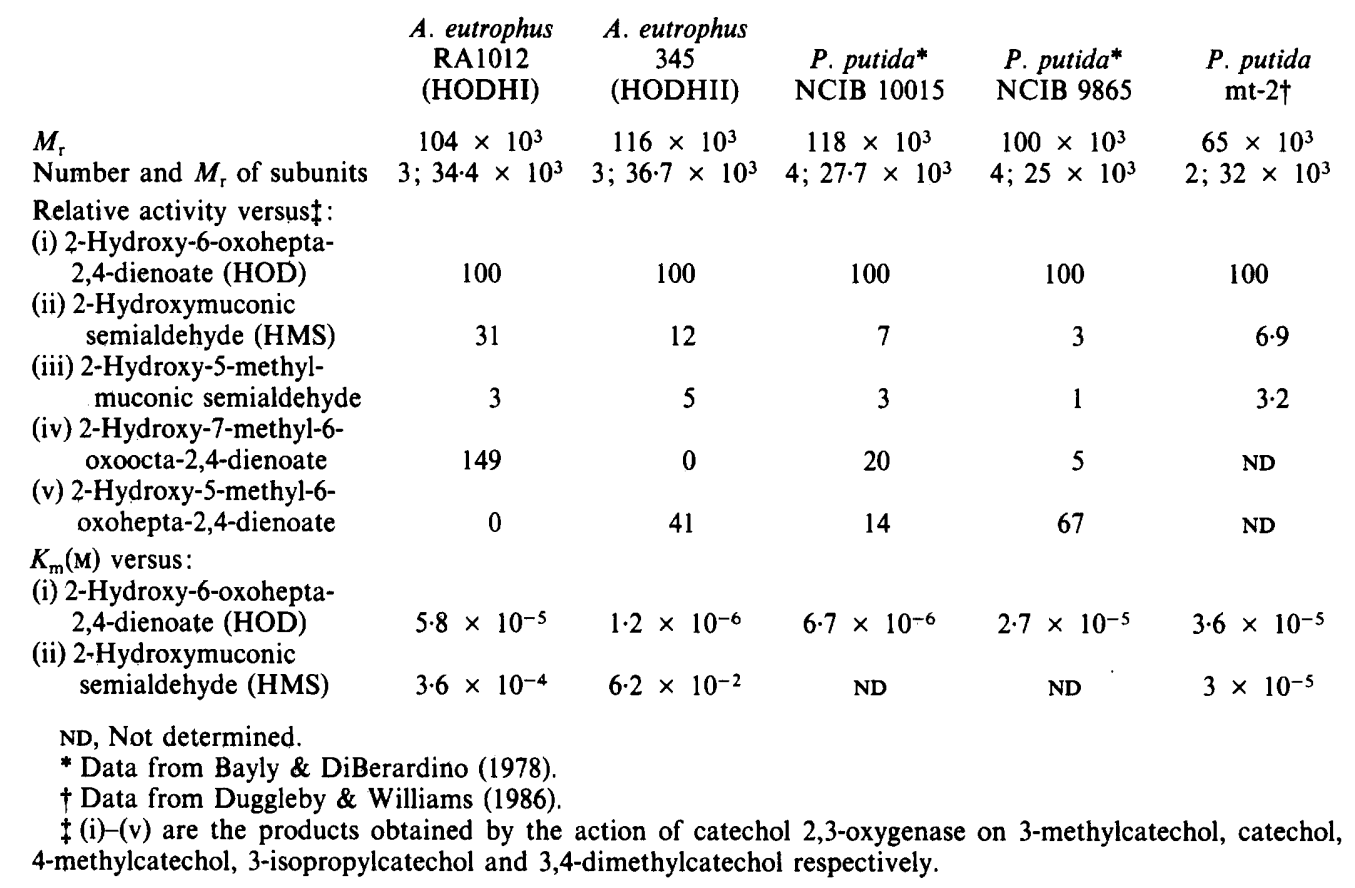

\section{Kinetic properties}

The comparative rates of hydrolysis of the meta-cleavage products of catechol and some alkylsubstituted catechols by HODHI and HODHII, and the $K_{\mathrm{m}}$ values of these enzymes, are shown in Table 3. Relative to HOD (the meta-cleavage product of 3-methylcatechol), HMS was attacked by HODHI at about three times the rate of HODHII. There was a marked difference between the $K_{\mathrm{m}}$ of HODHII for the meta-cleavage products of catechol and 3-methylcatechol, whereas, with HODHI, the $K_{\mathrm{m}}$ values for these substrates were much closer. Significant differences were also found when the meta-cleavage products of 3-isopropylcatechol and 3,4dimethylcatechol were used as substrates (Table 3).

\section{Inhibition/stimulation of hydrolase activity}

The effect of different cations, a chelating agent and a thiol-specific agent on the activity of HODHI and HODHII against HOD was examined after the purified enzymes had been incubated at $20^{\circ} \mathrm{C}$ for $30 \mathrm{~min}$ with the compounds at a final concentration of $5 \mathrm{~mm}$. Both hydrolases were substantially inactivated $(90-100 \%)$ by $\mathrm{Zn}^{2+}$ and $\mathrm{Cu}^{2+}$, and HODHI was inactivated to a much greater extent $(90 \%)$ by $p$-chloromercuribenzoate than was HODHII $(35 \%)$. The greater sensitivity of HODHI to the latter reagent may indicate either a greater availability of the thiol groups of the enzyme to react with that compound than is the case with HODHII or that HODHII possesses a relatively labile thiol group that has been modified during the purification processes. The activity of HODHI was decreased by about $50 \%$ in the presence of $\mathrm{Mn}^{2+}$ whereas HODHII activity was stimulated to a level about $50 \%$ higher when $\mathrm{Mn}^{2+}$ was present. EDTA showed no significant stimulatory or inhibitory effect. No differences in the above results were obtained when the hydrolases were dialysed for $24 \mathrm{~h}$ against $0.05 \mathrm{M}-\mathrm{Tris} / \mathrm{HCl}$ pH 8.0 containing 0.05 M-EDTA before being tested. 
The two hydrolases, HODHI and HODHII, purified from A. eutrophus strain 345 are similar to one another in several respects, but also show important differences.

HODHI and HODHII have similar $M_{\mathrm{r}}$ values and both appear to be trimers whose subunits are of similar size and are not linked by disulphide bonds. They have similar $\mathrm{pH}$ profiles, are inactivated by heat at similar temperatures, and their overall amino acid compositions differ significantly only in the larger number of valine residues present in HODHI. Immunodiffusion experiments showed that the two hydrolases are immunologically distinct and they therefore cannot share any common antigenic determinants on their surfaces.

There is, however, a considerable difference in their kinetic properties as shown by the higher catalytic activity and greater $K_{\mathrm{m}}$ of HODHI against HMS as compared to HODHII. This is consistent with the report of Hughes et al. $(1984 a, b)$ that strain 345 metabolizes phenol exclusively via a hydrolytic cleavage of HMS and not by the action of an aldehyde dehydrogenase as has been shown in some $P$. putida strains (Murray et al., 1972; Sala-Trepat et al., 1972; Wigmore et al., 1974) and in A. eutrophus strain 335 (ATCC 17697) (Hughes \& Bayly, 1983).

Some properties of other isofunctional HODHs from three strains of $P$. putida have been reported. Bayly \& DiBerardino (1978) isolated hydrolases from each of $P$. putida NCIB 10015 and $P$. putida NCIB 9865, and Duggleby $\&$ Williams (1986) purified a hydrolase from $P$. putida mt-2. The latter authors have made comparisons of some of the properties of the $P$. putida hydrolases and Table 3 summarizes some properties of the hydrolases now reported from $A$. eutrophus and those from the $P$. putida strains. It should be noted that the comparative activities against different substrates in $P$. putida $\mathrm{mt}-2$ (Table 3 ) are calculated from $V_{\max }$ values whereas the remaining data are derived from assays in which the substrate concentrations in some cases may have been below saturation levels. With the exception of the enzyme from P. putida mt-2, $M_{\mathrm{r}}$ values of the enzymes are similar and, while the subunit $M_{\mathrm{r}}$ values of all five hydrolases lie in the range $25-37 \times 10^{3}$, the apparent number of subunits varies from two to four.

Marked differences are apparent in the relative activity of the enzymes against the same substrates, which may reflect that the strains have evolved to enhance their catalytic activities towards compounds which they may encounter as metabolites arising from different growth substrates. The high activity of HODHI towards the meta-cleavage product of 3isopropylcatechol stands out from the other results. This compound, 2-hydroxy-7-methyl-6oxoocta-2,4-dienoate, would be an intermediate if 3-isopropylbenzene was metabolized via 3isopropylcatechol as was suggested by Gibson \& Subramanian (1984), but A. eutrophus RA1012 has not been tested for growth on 3-isopropylbenzene. The $K_{\mathrm{m}}$ values for the hydrolases tested show similar preferential binding capacities for the same substrates except for HODHII to HMS. This compound would not be a metabolite when $m$-toluate was metabolized by $A$. eutrophus 345 and hence there would have been no pressure for HODHII to have evolved to attack that compound.

There is some immunological cross-reactivity between the various hydrolases. Duggleby $\&$ Williams (1986) reported a cross-reaction between antiserum to the hydrolase from $P$. putida mt2 and crude extract of phenol-induced $P$. putida NCIB 10015. In this study, although antisera to HODHII did not react with a crude extract of the $m$-toluate-grown $P$. putida mt-2, both purified HODHII and a crude extract of the latter strain gave a line of identity with antisera to the hydrolase purified from $P$. putida NCIB 9865.

The comparative information available on the properties of the five HODHs now purified show several points of similarity between the enzymes. However, on the evidence at present available, it is not possible to draw definite conclusions as to their evolutionary relatedness and. as Duggleby \& Williams (1986) have stated, further such evidence 'is much more likely to come from molecular comparisons of the coding DNA ....

This work was supported in part by an Australian Research Grants Scheme grant no. D28015161l and by a Monash University Special Research Grant no. 15/81. E. J.L. Hughes was supported by a Monash graduate student grant. 


\section{REFERENCES}

Bayly, R. C. \& DiBerardino, D. (1978). Purification and properties of 2-hydroxy-6-oxo-2,4-heptadienoate hydrolase from two strains of Pseudomonas putida. Journal of Bacteriology 134, 30-37.

Bayly, R. C., Dagley, S. \& Gibson, D. T. (1966). The metabolism of cresols by species of Pseudomonas. Biochemical Journal 101, 293-301.

Bayly, R. C., Chapman, P. J., Dagley, S. \& DiBerardino, D. (1980). Purification and some properties of maleylpyruvate hydrolase and fumarylpyruvate hydrolase from Pseudomonas alcaligenes. Journal of Bacteriology 143, 70-77.

DAvis, B. J. (1964). Disc electrophoresis. Method and application to human serum proteins. Annals of the New York Academy of Sciences 121, 404-427.

Duggleby, C. J. \& Williams, P. A. (1986). Purification and some properties of the 2-hydroxy-6oxohepta-2,4-dienoate hydrolase (2-hydroxymuconic semialdehyde hydrolase) encoded by the TOL plasmid pWW0 from Pseudomonas putida mt-2. Journal of General Microbiology 132, 717-726.

Gibson, D. T. \& Subramanian, V. (1984). Microbial degradation of aromatic hydrocarbons. In Microbial Degradation of Organic Compounds, pp. 181252. Edited by D. T. Gibson. New York: Marcel Dekker.

Hughes, E. J. L. \& BaYLY, R. C. (1983). Control of catechol meta-cleavage pathway in Alcaligenes eutrophus. Journal of Bacteriology 154, 1363-1370.

Hughes, E. J. L., Bayly, R. C. \& SKurRay, R. A. (1984a). Characterization of a TOL-like plasmid from Alcaligenes eutrophus which controls the expression of a chromosomally encoded $p$-cresol pathway. Journal of Bacteriology 158, 73-78.
Hughes, E. J. L., Bayly, R. C. \& Skurray, R. A. $(1984 b)$. Evidence for isofunctional enzymes in the degradation of phenol, $m$ - and $p$-toluate and $p$-cresol via catechol meta-cleavage pathways in Alcaligenes eutrophus. Journal of Bacteriology 158, 79-83.

KEAT, M. J. \& HOPPER, D. J. (1978). p-Cresol and 3,5xylenol methylhydroxylases in Pseudomonas putida NCIB 9869. Biochemical Journal 175, 649-658.

Murray, K., Duggleby, C. J., Sala-Trepat, J.-M. \& Williams, P. A. (1972). The metabolism of benzoate and the methylbenzoates via the meta cleavage pathway by Pseudomonas arvilla mt-2. European Journal of Biochemistry 28, 301-310.

Sala-Trepat, J.-M., Murray, K. \& Williams, P. A. (1972). The metabolic divergence in the meta cleavage of catechols by Pseudomonas putida NCIB 10015. Physiological significance and evolutionary implications. European Journal of Biochemistry 28, 347-356.

Tack, B. F., Chapman, P. J. \& Dagley, S. (1972). Purification and properties of 4-hydroxy-4-methyl-2oxoglutarate aldolase. Journal of Biological Chemistry 247, 6444-6449.

WEBER, K. \& OSBORN, M. (1969). The reliability of molecular weight determinations by dodecyl sulphate-polyacrylamide gel electrophoresis. Journal of Biological Chemistry 244, 4406-4412.

Wigmore, G. J., Bayly, R. C. \& DiBerardino, D. (1974). Pseudomonas putida mutants defective in the metabolism of the products of meta fission of catechol and its methyl analogues. Journal of Bacteriology 120, 31-37.

YPHANTIS, D. A. (1964). Equilibrium ultracentrifugation of dilute solutions. Biochemistry 3, 297-317. 